\title{
Household Food Insecurity is Associated with Undernutrition among Primary School Children in Aden Governorate, Yemen
}

\author{
Shadha Anwar Ahmed Esmail ${ }^{1}$, Roslee Rajikan ${ }^{1 *}$ \\ ${ }^{1}$ Dietetic Program, Faculty of Health Science, Universiti Kebangsaan Malaysia, \\ Kuala Lumpur 50300, Malaysia
}

\begin{abstract}
Food insecurity is typically linked with undernutrition. However, there is little published data available on the association between household food insecurity and undernutrition status of the primary school children aged 6-12 years in Aden, Yemen. The purpose of this research was to analyse the association between household food insecurity and the undernutrition status of the children. A cross-sectional study was carried out among primary school children from grades I to VI in the government schools $(\mathrm{n}=525)$. A simple questionnaire, face-to-face interview with parents, and Radimer/Cornell hunger and food insecurity tool were utilized for the data collection. Anthropometric measurements (weight \& height) of the children were also recorded. Upon analysis, $70 \%$ of the surveyed children came from a food secure household, whilst 30\% experienced some type of food insecurity. Education level of the father $(p<0.03)$, employment of the mother $(p<0.00)$, overall household income $(p<0.01)$, income per capita $(p<0.01)$ and number of working persons per household $(p<0.00)$ were all significant variables associated with food insecurity among these households. Results also showed that the frequency of underweight, stunting and wasting among the children was $19 \%, 17 \%$ and $10 \%$, respectively. Significant associations were found between household food insecurity and the state of being underweight, stunting and wasting. Importantly, the association between household food insecurity and undernutrition status continued even after adjustment for significant variables. In conclusion, household food insecurity was significantly associated with undernutrition status of the primary school children in Aden's Governorate, Yemen.
\end{abstract}

Keywords: food insecurity, nutritional status, primary school children

\section{INTRODUCTION}

Food insecurity is characterized by a reduction in food intake and disruption of the eating pattern due to lack of money in the household or lack of the food resources, which persist, for a long period resulting in malnutrition. This phenomenon is more obvious among children and women (Unisa et al. 2016; FAO/ IFAD/UNICEF/WFP/WHO 2019). FAO (2012) defined food security as "A situation that exists, when secure access to an appropriately nutritious diet is coupled with a sanitary environment, adequate health services and care, in order to ensure a healthy and active life for all household members".

The studies of association between household food security and undernutrition, food consumption inadequacy, decreased cognitive and educational success, and psychosocial difficulties among children are numerous (Hackett et al. 2009; FAO 2012; Ihab et al. 2015). However, in Yemen studies of association between food insecurity and undernutrition among low socio-economic households are limited (Saaka \& Osman 2013).

Yemen is a desert country in the Middle East on the southern tip of the Arabian Peninsula and it consists of 22 governorates and five islands. Sana'a is the political capital of Yemen, and Aden is the economic capital (Factbook 2016). Since 1990, the two countries (South and North Yemen) formally unified as the Republic of Yemen and a southern secessionist movement and the transitory civil war in 1994 had been quickly suppressed (Day 2010), which resulted in the exclusion of South Yemen and specifically Aden in many studies.

"Corresponding Author: tel: +603-92897511, email: roslee@ukm.edu.my 
In Yemen, specifically in Aden, there is no a single study conducted on the association between nutritional status among school children and household food insecurity. In addition, among the rational to carried out this study is that nearly one third of school children in Aden governorate found to be malnourished where high prevalence of underweight (23.4\%), stunting (16.7\%) and wasting (19.3\%) were reported (MOPHP/ $\mathrm{UNICEF/FMF} \mathrm{2015).} \mathrm{Moreover,} \mathrm{studies} \mathrm{on}$ household food insecurity have been conducted widely across Yemen (Kabbani \& Wehelie 2005; IFPRI 2012), nevertheless, these studies neither included Aden governorate nor school children nor the association with health status of low socio-economic school children. In addition, the majority of undernutrition studies focused on children under five years and overlooking the primary school children group (Eshaq et al. 2017; Dyer 2018).

Food insecurity might be a significant contributing factor of undernutrition and the core variable of undernutrition among low socioeconomic households. Thus, identifying the association of household food insecurity and children undernutrition will assist in planning and implementation of proper interventions to prevent or reduce undernutrition among school children. Findings from this study will also provide a reliable and valid resources for similar studies and for the on-going researches on ways to improve nutritional status among school children with food insecurity. Hence, this study was aimed to identify the association of food security and undernutrition among primary school children in Aden's governorate and to explore the contributing aspects and outcomes of food insecurity among households in this governorate.

\section{METHODS}

\section{Design, location, and time}

A cross-sectional study was carried out amongst primary school children enrolled in the grades I to VI in government schools, located at the seven districts of Aden governorate from January to May 2013. Aden governorate is a coastal region covering a total area of $1,114 \mathrm{~km}^{2}$, and has a population of 751,800 . Similarly, to other part of Yemen, the majority of population are young, $48 \%$ are under 15 years, and the median age is 18.1 years. Aden has a lower than an average poverty level of $17 \%$ among its 16,500 registered households, while food insecurity with moderate hunger of $20-30 \%$ (WFP 2012). The economy of the city depends on its seaport, and it has the highest rate of unemployment (28\%) in the country (CSO 2011).

\section{Sampling}

Aden consists of seven districts (AlMansura, Al Mualla, Al-Shaikh Othman, Altawahi, Crater, Dar Sad and Khormaksar); each district has multiple schools (Total 72 primary Schools). Lists of government schools within each district were provided by the Education office and one school was selected randomly by simple random sampling technique from each district. Schools were selected according to the inclusion criteria (i.e. government schools and mixed gender schools).

Subjects were randomly selected from the seven schools. Sample sizes was calculated through the simplified formula for proportions and 680 children were then selected. These children were considered of low socioeconomic level, because only children of low socioeconomical level enrolled in the governmental schools (UNICEF 2016).

A total of 680 questionnaires and consent forms were administered to the randomly slecetd students, by the researcher with the help of the teachers (14 students in each grade/school). Next day, the researcher recollected the questionnaire. Survey data was excluded from analysis when surveys had missing information, student failed to return the questionnaire, or when the parents did not give their consent. Twins or siblings from the same household were also excluded from the study to prevent duplication of household data. After exclusion, 525 subjects were included in the study, representing $76 \%$ of the respondents. The parents of these children were then approached and requested for a personal interview. Personal interviews were done during house visits by the researcher and the assistant. This research was authorized by the Yemeni Medical Council (Reference number 84521).

\section{Data collection}

Data was collected by administering the socio-demographic questionnaire to students from grade I-IV in each selected school. Each questionnaire had an informed consent form 
which requires participants' parents to sign after understanding the purpose of the study. The questionnaire consisted of two parts: (A) general information about the participant such as age, level of study and anthropometric measurements such as weight, height and BMI, and (B) information on the family such as education of parents, number of children in the house, household size, employment status of the parents, total household income and expenditures. After collecting the questionnaires, anthropometric measurements (weight and height) were taken and compared with growth charts (De Onis 2007) using computer application Anthro-plus software for Windows 10.

Weight and height of the children were used to compute age-and sex-specific Z-scores to obtain statistics on underweight, wasting, and stunting. Weight for Age Z-score (WAZ) was used as an indicator for underweight, Height-forAge Z-score (HAZ) was used as an indicator for stunting (chronic malnutrition), and Weight-for-
Height Z-score (WHZ) was used as an indicator for wasting (acute malnutrition). Z-scores were calculated based on the median values of the WHO Reference Population. The children were categorized into three groups, (i) Z-scores below -2 standard deviations (SD) of the WHO Reference Population medians i.e. malnourished, (ii) Z-scores above $-2 \mathrm{SD}$ and below $+2 \mathrm{SD}$ i.e. normal, and those above +2 SD were overweight/ obese. Three consecutive readings were obtained for each measurement, and the mean was recorded.

The parents were approached for interview through phone numbers provided on the questionnaire. The researcher and the assistant then approached parents' houses, according to the parents' time of convenience. Household food security was measured utilizing the Radimer/Cornell hunger and food insecurity tool (Radimer et al. 1992). This tool consisted of 12 items (Table 1) that were translated into the Arabic language. The tool was tested via face,

Table 1. Radimer/Cornell hunger and food insecurity tool

Household level

1. Do you stress whether your food will go out prior to you obtain money to purchase more?

2. I lacked the foods that I required to create a meal and I did not have money to obtain more food.

3. The food that I purchased simply did not last and I did not have money to obtain more.

4. I stress over where the following day's food is going to come from.

Individual level

5. I cannot manage to consume the way I should.

6. Can you manage to consume properly?

7. How frequently are you starving, but you do not eat because you cannot manage sufficient food?

8. Do you consume less than you believe you should because you do not have sufficient money for food?

Child level

9. I cannot provide my child (ren) a balanced meal because I cannot afford that.

10. I cannot manage to feed my child (ren) the way I believe I should.

11. My child (ren) is/are not consuming sufficient because I just cannot provide sufficient food.

12. I know my child (ren) is/are starving sometimes, but I just cannot provide more food.

To categories the intensity of food insecurity; Food secure: Negative response to all items; Household insecure: Positive response to one or more items (1-4) but not to adult or child level items; Individual insecure: Positive response to one or more of items (5-8) but not to items (9-12); Child hunger: Positive response to items (9-12) 
construct as well as content for validity and items reliability, respectively. The reliability test produced a Cronbach's alpha of 0.87. During each interview, the 12 questions were answered by one of the parents, predominantly the mothers with the absence of other adults at home, hence; it was found that the presence of other adults could distort the reliability of the answers (Mohamadpour et al. 2012). The household food insecurity tool involves four components: amount of the food, fineness of the food, food adequacy, and assurance of obtaining food. The household was considered as food secure when the answers given by the interviewee were "not true" or "never". Conversely, they were food insecure when the answers were "sometimes" or "always".

\section{Data analysis}

All the statistical analyses were carried out using the Statistical Package for Social Sciences version 20 (SPSS Inc., Chicago, IL, USA). Descriptive statistics using mean \pm SD (standard deviation) were, firstly carried out and were utilized to compare the food-secure and food-insecure household according to their demographic, socio-economic, and anthropometric variables. Chi-square test and t-test were used for categorical and continuous variables in comparing differences between the food secure and insecure households. While, logistic regression was used in both the binary and multinomial analysis to find the association between malnutrition and household's food insecurity. Significance level was set at $p<0.05$.

\section{RESULTS AND DISCUSSION}

\section{Household food insecurity}

Households were categories into one of four food insecurity categories using the Radimer/ Cornell tools. Seventy percent $(n=367)$ of the households were food secure, and 30\% ( $\mathrm{n}=158)$ were food insecure. Eighty-one households or $15 \%$ had actually been encountered the lowest serious degree of food insecurity and were categories as "household food insecure." These households were lacked foods and unsure of their capability to provide the food, and may have adjusted the quality of the family member diet. Another $8 \%$ experienced individual or adult type of food insecurity and $7 \%$ experienced child hunger (Table 2). Which indicate parents could not get enough amount of food or good quality food for their children.

Our finding showed a much lower compared to food security survey carried out in Yemen in 2013 , which declared that $48 \%$ of households could be categorized as food insecure (WFP 2014). However, the household food insecurity reached more than $60 \%$ after the escalation of conflict in 2015 causing an immediate appeal for urgent humanitarian assistance (WFP 2017). The increasing prevalence of food insecure households was attributed to political instability and an increase in food prices. Despite of humanitarian assistance more than 20 million $(67 \%)$ were food insecure in Yemen (WFP 2020).

Considering the difference in our finding compared to the more comprehensive national review on food insecurity prevalence, this might be due to the fact that our instrument relied on qualitative indicator. The Radimer/Cornell 12 item questionnaire was found to be a highly reliable tool for assessing food insecurity in household with children (Tutunchi et al. 2020). Eventhough the Radimer/Cornell hunger tool had high reliability and developed in perspectives to women, who had experienced hunger, the tool is a qualitative tool. This makes the reporting subjective and may lead toward reporting bias, where mothers may be ashamed to admit their household problem. Therefore, future studies could consider utilizing objective tools such as the Household Dietary Diversity Score (HDDS) in combination with qualitative tool to reduce or prevent the possible bias that may arise. Ashby et al. (2016) in their systemic review found that other tools such the Cornell Child Food Security Measure, the CCHIP tool, the Hager two-item screen, the Girard four-point tool, the Kuyper past

Table 2. Prevalence of food security among the households $(\mathrm{n}=525)$

\begin{tabular}{lcc}
\hline \multicolumn{1}{c}{ Category of food security } & $\mathrm{n}$ & $\%$ \\
\hline Food secure & 367 & 69.9 \\
Household food insecure & 81 & 15.4 \\
Individual food insecure & 41 & 7.8 \\
Child hunger & 36 & 6.9 \\
\hline
\end{tabular}


food security tool, the Household Food Security Access Scale and the Townsend Food Behavior Checklist can also be utilized to determine food insecurity. All the tools measure food insecurity in regard to accessibility to food on individuals or households albeit at varying level of consistency and validity. In addition, the Household Food Security Survey Module (HFSSM) and its variation are recommended by Department of Agriculture (USDA) to measure household food security (Marques et al. 2015). However, FSSM might not totally record the extent and magnitude of food security, as its measurement is restricted to one dimension of food security (Marques et al. 2015; Ashby et al. 2016).

\section{Association of the household characteristics and food security}

A total of 525 households were included in this study. Majority of the fathers were in the 41-80 years old age group, whereas, the majority of mothers were in the age group 15-40 years (Table 3).

In this study, parents in the food insecure households were much more educated contrasted to previous studies (Othman 2014; Al-Sonini 2015) carried out in Yemen. In agreement with this study, Arzhang et al (2019) in their study found that higher education of father's was associated with household insecurity. Moreover, Abdullah et al. (2019) reported that higher parent's education is associated with a food secure household. Large family size might explain the high-level of food insecurity among highly educated fathers in the present study. This study also found that large household size (62\%), high percentage of unemployed mothers $(88 \%)$, and households which had only one working person $(71 \%)$ were all significantly associated with food insecurity.

Mother's employment, overall household income and income per capita in the households with food insecurity showed significant mean differences with those with food insecurity $(\mathrm{p}<0.00 ; \quad \mathrm{p}<0.01 ; \quad \mathrm{p}<0.01)$. Many previous studies have reported an association between the mother's employment and household food security, in relation to fathers being the only breadwinner for the family, providing food and shelter to his family members. In agreement with the present study, Shariff et al. (2008) reported an association between employment of the mother and household food security, they explained that working mothers contributed to the household income and food expenditure thus preventing household food insecurity.

This study also found that the number of employed persons per household had a significant association with the household food insecurity. The proportions of households with multiple working persons were higher among secure households compared to insecure households. This finding is consistent with Ihab et al. (2015), because they observed that the addition of one more employed member per household resulted additional income that reduced food insecurity.

Hence, education level of the fathers, employment of the mothers, total monthly income, income per capita and the number of working persons per household were found to have a significant association with food insecurity among households.

\section{Undernutrition status}

The anthropometric characteristics of the Yemeni children, who were the subject of this study were provided in Table 4 . The overall prevalence of underweight among children was $19 \%$, whilst the prevalence of stunting was $17 \%$ and the wasting was $10 \%$. Overall, the mean value for weight was $27.2 \pm 7.28 \mathrm{~kg}$ and for height was $129.4 \pm 14.67 \mathrm{~cm}$. There was a significant mean difference between food-secure and foodinsecure children in terms of HAZ $(p<0.00)$. This finding is in agreement with a study carried out by Ihab et al. (2015) reported that household food insecurity was associated with chronic undernutrition of the school children.

\section{Association of household insecurity and undernutrition status}

Among the result of this study, the household food insecurity is a significant predictor of the undernutrition (stunting, wasting and underweight) among school children in Aden, Yemen. The association remain significant after adjustment. The covariates in the multiple logistic regression model included education level of the fathers, employment of mothers, number of working persons in the household and total income. Children in food-insecure households had a higher risk for underweight, stunting and wasting compared with children in food secure households $(p<0.05) \quad$ (Table 5). The results showed that school children in food insecure 
Esmail \& Rajikan

Table 3. Sociodemographic-economic features of food secure and insecure household $(n=525)$

\begin{tabular}{|c|c|c|c|c|c|}
\hline \multirow{2}{*}{ Characteristics } & \multicolumn{2}{|c|}{ Food secure $(\mathrm{n}=367)$} & \multicolumn{2}{|c|}{ Food insecure $(\mathrm{n}=158)$} & \multirow{2}{*}{$\mathrm{p}$} \\
\hline & n $(\%)$ & $\operatorname{Median} \pm$ SD & $\mathrm{n}(\%)$ & Median \pm SD & \\
\hline Age in years (father) & & $43 \pm 8.94$ & & $41 \pm 11.27$ & 0.25 \\
\hline $20-40$ & $143(39.0)$ & & $74(46.8)$ & & \\
\hline $41-80$ & $224(61.0)$ & & $84(53.2)$ & & \\
\hline Age in years (mother) & & $38 \pm 6.20$ & & & \\
\hline $15-40$ & $257(70.0)$ & & $124(78.5)$ & $35 \pm 6.38$ & 0.76 \\
\hline $41-80$ & $110(30.0)$ & & $34(21.5)$ & & \\
\hline Education level (father) & & $3.0 \pm 1.12$ & & $3.0 \pm 1.25$ & $0.03^{*}$ \\
\hline No formal education & $63(17.2)$ & & $36(22.8)$ & & \\
\hline Primary \& secondary school & $182(49.6)$ & & $66(41.8)$ & & \\
\hline Diploma/tertiary foundation & $122(33.2)$ & & $56(35.4)$ & & \\
\hline Education level (mother) & & $2.00 \pm 1.04$ & & $2.00 \pm 1.00$ & 0.56 \\
\hline No formal education & $107(29.2)$ & & $43(27.2)$ & & \\
\hline Primary \& secondary school & $201(54.8)$ & & $94(59.5)$ & & \\
\hline Diploma/tertiary foundation & $59(16.1)$ & & $21(13.3)$ & & \\
\hline Number of children & & $4.00 \pm 1.84$ & & $5.00 \pm 1.88$ & 0.95 \\
\hline $1-3$ & $125(34.1)$ & & $59(37.3)$ & & \\
\hline $4-6$ & $190(51.8)$ & & $75(47.5)$ & & \\
\hline$\geq 7$ & $52(14.1)$ & & $24(15.2)$ & & \\
\hline Household size & & $7.00 \pm 2.56$ & & $8.00 \pm 2.32$ & 0.22 \\
\hline $3-6$ & $140(38.1)$ & & $50(31.6)$ & & \\
\hline $7-10$ & $188(51.2)$ & & $98(62.0)$ & & \\
\hline$\geq 11$ & $39(10.7)$ & & $10(6.3)$ & & \\
\hline Employment (fathers) & & & & & 0.08 \\
\hline Working & $287(78.2)$ & & $118(74.7)$ & & \\
\hline Not working & $80(21.8)$ & & $40(25.3)$ & & \\
\hline Employment (mothers) & & & & & $0.00^{*}$ \\
\hline Working & $62(16.9)$ & & $19(12.0)$ & & \\
\hline Housewife & $305(83.1)$ & & $139(88.0)$ & & \\
\hline Total household income (USD) ${ }^{* *}$ & & $336 \pm 263.2$ & & $293 \pm 213.0$ & $0.01^{*}$ \\
\hline $0-300$ & $51(13.9)$ & & $31(19.6)$ & & \\
\hline $301->1000$ & $173(47.1)$ & & $73(46.2)$ & & \\
\hline Income per capita (USD) ${ }^{* *}$ & & $51 \pm 45.38$ & & $42 \pm 36.05$ & $0.01^{*}$ \\
\hline $0-150$ & $233(63.5)$ & & $110(69.6)$ & & \\
\hline $151-300$ & $94(25.6)$ & & $38(24.1)$ & & \\
\hline Working /household & & & & & $0.00^{*}$ \\
\hline None & $26(7.1)$ & & $18(11.4)$ & & \\
\hline One & $237(64.6)$ & & $112(70.9)$ & & \\
\hline More than one & $104(28.3)$ & & $28(17.7)$ & & \\
\hline Monthly household expenditure (USD) ${ }^{* *}$ & & $434 \pm 232.4$ & & $409 \pm 246.4$ & 0.55 \\
\hline $0-300$ & $20(5.4)$ & & $14(8.9)$ & & \\
\hline $301->1000$ & $91(24.8)$ & & $48(30.4)$ & & \\
\hline
\end{tabular}

" $\mathrm{p}<0.05 ;{ }^{* *} 1$ USD $=215 \mathrm{Ry}$

Chi-square t-test 
Household food insecurity among Yemeni school children

Table 4. Undernutrition status of school children in Yemen $(n=525)$

\begin{tabular}{|c|c|c|c|c|c|c|c|}
\hline \multirow{2}{*}{ Anthropometric Index } & \multicolumn{2}{|c|}{$\begin{array}{l}\text { Food secure } \\
(\mathrm{n}=367.70 \%)\end{array}$} & \multicolumn{2}{|c|}{$\begin{array}{l}\text { Food insecure } \\
(\mathrm{n}=158.30 \%)\end{array}$} & \multicolumn{2}{|c|}{ Overall $(\mathrm{n}=525)$} & \multirow{2}{*}{$\mathrm{p}$} \\
\hline & $(\%)$ & Mean \pm SD & $(\%)$ & Mean \pm SD & $(\%)$ & Mean \pm SD & \\
\hline WAZ & & $1.94 \pm 0.22$ & & $1.51 \pm 0.50$ & & $1.82 \pm 0.38$ & $0.00^{\mathrm{a}}$ \\
\hline Underweight ${ }^{*}$ & $19(5.2)$ & & 77 (48.7) & & $96(18.5)$ & & \\
\hline Normal $^{* *}$ & $348(94.8)$ & & $81(51.3)$ & & $424(80.5)$ & & \\
\hline Overweight $^{* * *}$ & $0(0)$ & & $2(0.8)$ & & $5(0.9)$ & & \\
\hline HAZ & & $1.94 \pm 0.23$ & & $1.58 \pm 0.49$ & & $1.86 \pm 0.37$ & $0.00^{\mathrm{a}}$ \\
\hline Stunting* & $21(5.7)$ & & $66(41.8)$ & & $87(16.7)$ & & \\
\hline Normal $^{* *}$ & $346(94.3)$ & & $92(58.2)$ & & $438(83.3)$ & & \\
\hline WAH & & $1.96 \pm 0.19$ & & $1.75 \pm 43$ & & $1.89 \pm 0.30$ & $0.01^{\mathrm{a}}$ \\
\hline Wasting $^{*}$ & $14(3.8)$ & & $39(24.7)$ & & $53(10.1)$ & & \\
\hline Normal $^{* *}$ & $353(96.2)$ & & $119(75.3)$ & & $462(89.9)$ & & \\
\hline
\end{tabular}

"Underweight/stunting/wasting: <-2 SD; ${ }^{* *}$ Normal: >-2 SD - <+2 SD; ${ }^{* * *}$ Overweight/obese: >+2 SD; ${ }^{a}$ Independent t-test

households had 17 (AOR=17.44; CI:10.6731.24) times more risk to be underweight than those in the food secure household. Similarly, children in the food insecure household had 11 (AOR=11.98; CI:7.01-20.67) times more risk to be stunted compared to children in the food secure household. In addition, the wasting in food insecure households was 9 (AOR=9.12; CI:5.1116.03) times greater than among children in the food secure household.
This study is important, because it reveals a significant association between household food insecurity and undernutrition among children. In agreement with this study, Hackett et al. (2009) in Antioquia, Colombia, reported a high level of underweight, stunted and wasted children among food insecure households and a significant association between food insecurity status, stunting and underweight with no association with wasting. Likewise, Ihab et al.

Table 5. Association of household food insecurity and undernutrition of the children $(n=525)$

\begin{tabular}{|c|c|c|c|c|c|}
\hline \multirow{2}{*}{ Nutritional status \& type of household } & \multicolumn{3}{|c|}{ Simple logistic regression } & \multicolumn{2}{|c|}{ Multiple logistic regression } \\
\hline & OR $(95 \% \mathrm{CI})$ & $\mathrm{p}$ & B & $\operatorname{AOR}^{*}(95 \% \mathrm{CI})$ & $\mathrm{p}$ \\
\hline \multicolumn{6}{|l|}{ Underweight } \\
\hline Food secure & 1 & & & 1 & \\
\hline Food insecure & $17.41(9.93-30.39)$ & 0.00 & 2.857 & $17.44(10.67-31.24)$ & 0.02 \\
\hline \multicolumn{6}{|l|}{ Stunting } \\
\hline Food secure & 1 & & & 1 & \\
\hline Food insecure & $11.82(6.87-20.32)$ & 0.00 & 2.470 & $11.98(7.01-20.67)$ & 0.01 \\
\hline \multicolumn{6}{|l|}{ Wasting } \\
\hline Food secure & 1 & & & 1 & \\
\hline Food insecure & $8.26(4.33-15.75)$ & 0.00 & 2.112 & $9.12(5.11-16.03)$ & 0.04 \\
\hline
\end{tabular}


(2015) reported that household food insecurity was associated with underweight as well as stunting while, wasting did not show a significant association with food insecurity status among school children in Malaysia. Contrary, Mumena (2016), reported no association between food insecurity and any anthropometric measures.

Radimer/Cornell food security instrument was useful in determining food security in household or individuals. However, it can be complimented with the measurement of Dietary Diversity Indicator, recommended by FAO (FAO 2010), which assess nutritional adequacy of individuals diets as well as the economic ability of a household to access a variety of food.

When considering the results of this study it should be bear in mind that this research was subject to some limitations. Firstly, this study was cross-sectional, so there has actually been no follow-up and; consequently, there was no possibility for subjects to leave the study. Secondly, the sample was restricted to one area of Yemen.

\section{CONCLUSION}

This study found a significant association between household food insecurity and undernutrition among primary school children in Aden, Yemen. The father's education level, mother's employment, monthly household income and the number of working persons in the household were all significant variables associated with undernutrition thus considered as covariate in further analysis. The novel outcome of this study was that nutritional status among children within the governmental schools was associated with their household food insecurity, even after adjusting for the covariates, indicating that household food insecurity is a major contributor of malnutrition among school children in Aden schools.

\section{ACKNOWLEDGEMENT}

The authors would like to thank the administration, children and families of schools for their support and cooperation in this research.

\section{AUTHOR DISCLOSURES}

The authors have no conflict of interest.

\section{REFERENCES}

Al-Sonini NAA. 2015. The effect of socioeconomic factors on the health indicators in Yemen. J Nat Sci Res 5(13):140-146.

Abdullah A, Zhou D, Shah T, Ali S, Ahmad W, Din IU, Ilyas A. 2019. Factors affecting household food security in rural northern hinterland of Pakistan. J Saudi Soc Agric Sci 18(2):201-210. https://doi. org/10.1016/j.jssas.2017.05.003.

Arzhang P, Gargari BP, Sarbakhsh P, Farzaneh H. 2019. Household food insecurity and associated factors among rural and urban high school students in Kurdish population of Iran. Prog Nutr 21(2):56-64. doi:10.23751/pn.v21i2-S.6320.

Ashby S, Kleve S, McKechnie R, Palermo C. 2016. Measurement of the dimensions of food insecurity in developed countries: A systematic literature review. Public Health Nutr 19(16):2887-2896. doi:10.1017/ S1368980016001166.

[CSO] Central Statistical Organization. 2011. Statistical Yearbook 2011. Sana'a (YM): CSO.

Day S. 2010. The Political Challenge of Yemen's Southern Movement. Washington DC (USA): Carnegie Endowment for International Peace.

De Onis M, Onyango AW, Borghi E, Siyam A, Nishidaa C, Siekmanna J. 2007. Development of a WHO growth reference for school-aged children and adolescents. Bull World Health Organ 85:660-667. doi: 10.2471/blt.07.043497.

Dyer O. 2018. Yemen: Number of children under 5 who have died from malnutrition may be as high as 85000 , says save the children. BMJ 363:k4949. https://doi.org/10.1136/ bmj.k4949.

Eshaq AM, Fothan AM, Jensen EC, Khan TA, Al-Amodi AA. 2017. Malnutrition in Yemen: An invisible crisis. The Lancet 389 (10064):31-32. https://doi.org/10.1016/ S0140-6736(16)32592-2.

Factbook. 2016. Yemen demographics profile 2016. http://www.indexmundi.com/ yemen/demographics_profile.html [Acecessed 8th November 2016].

[FAO] Food and Agriculture Organization. 2010. Guidelines for Measuring Household and 
Individual Dietary Diversity. Rome (IT): FAO.

[FAO] Food and Agriculture Organization. 2012. The State of Food Insecurity in the World 2012: Economic Growth is Necessary but nor Sufficient to Accelerate Reduction of Hunger and Malnutrition. Rome (IT): FAO.

[FAO/IFAD/UNICEF/WFP/WHO]. Food and Agriculture Organization, International Fund for Agricultural Development, United Nations International Children's Emergency Fund, World Food Program, World Health Organization. 2019. The State of Food Security and Nutrition in the World 2019. Safeguarding Against Economic Slowdowns and Downturns. Rome (IT): FAO.

Hackett M, Melgar-Quiñonez H, Alvarez MC. 2009. Household food insecurity associated with stunting and underweight among preschool children in Antioquia, Colombia. Rev Panam Salud Públ 25:506-510. doi: 10.1590/s1020-49892009000600006.

[IFPRI] International Food Policy Research Institute. 2012. Managing Transition in Yemen. An Assessment of the Costs of Conflict and Development Scenarios for the Future. Washington DC (USA): IFPRI.

Ihab AN Rohana AJ, Wan Manan WM, Wan Suriati WN, Zalilah MS, Mohamed Rusli A. 2015. Assessment of Food Insecurity and Nutritional Outcomes in Bachok, Kelantan. J Nutr Food Sci 5(3):373. http:// dx.doi.org/10.4172/2155-9600.1000373.

Kabbani N, Wehelie Y. 2005. Measuring Hunger and Food Insecurity in Yemen. Labour Economics Sessions of the 11th Annual Conference of the Economic Research Forum for the Arab Countries, Iran and Turkey (ERF). WorkingPaper 0419.5:1-20.

[MOPHP/UNICEF/FMF]. Ministry of Public Health and Population, United Nations Children's Fund, Field Medical Foundation. 2015. Nutrition and Mortality Survey in Aden Governorate, Yemen, 8-13 August report. Aden (YE): MOPHP, UNICEF, FMF.

Marques ES, Reichenheim ME, de Moraes CL. 2015 Household food insecurity: A systematic review of the measuring instruments used in epidemiological studies. Public Health Nutr 18(5):877892. doi:10.1017/S1368980014001050.

Mohamadpour M, Sharif ZM, Keysami MA. 2012. Food insecurity, health and nutritional status among sample of palmplantation households in Malaysia. J Health Popul Nutr 30(3):291-302. doi: 10.3329/jhpn.v30i3.12292.

Mumena WA. 2016. Food security and nutritional health of school-aged children in two Caribbean countries [Thesis]. Montreal: McGill University.

Othman N. 2014. A comparison between poverty index and wealth index in analyzing prevalence of malnutrition in Yemeni children [Thesis]. Yemen: Sana'a University.

Radimer KL, Olson CM, Greene JC, Campbell CC, Habicht JP 1992. Understanding hunger and developing indicators to assess it in women and children. $J$ Nutr Educ 24(1):36S-44S. https://doi.org/10.1016/ S0022-3182(12)80137-3.

Saaka M, Osman SM. 2013. Does household food insecurity affect the nutritional status of preschool children aged 6-36 months? Int J Popul Res 304169:1-12. https://doi. org/10.1155/2013/304169.

Shariff ZM, Bukhari SS, Othman N, Hashim N, Ismail M, Jamil Z, Kasim SM, Paim L, Samah BA, Hussein ZAM. 2008. Nutrition education intervention improves nutrition knowledge, attitude and practices of primary school children: A pilot study. Int Electron J Health Educ 11:119-132.

Tutunchi H, Ebrahimi-Mameghani M, AsghariJafarabadi M, Farrin N, Tabrizi S, VaghefMehrabany E, Ostadrahimi A. 2020. Is the modified household food security survey (HFSS) questionnaire a practical tool for screening food insecurity? Evidence from northwest of Iran. BMC Public Health 20:883. https://doi.org/10.1186/s12889020-09014-8.

[UNICEF] United Nations Children's Fund. 2016. Annual Report 2015 Yemen. New York (USA): UNICEF.

Unisa S, Chattopadhyay A, Fulpagare P, Sinha A. 2016. Food Security and Nutritional Status of Children in Maharashtra. IIPS Working Paper No. 12. India (IN): International Institute for Population Sciences. 
[WFP] World Food Programme. 2012. The State of Food Security and Nutrition in Yemen. Report June 2012. Rome (IT): WFP.

[WFP] World Food Programme. 2014. School feeding programs. Roma: World Food Program. documents.wfp.org/stellent/ groups/public/documents/resources/ wfp281540.pdf. [Accessed 3rd December 2016].
[WFP] World Food Programme. 2017. State of Food Insecurity in Yemen. Report April 2017. Rome (IT): WFP.

[WFP] World Food Programme. 2020. Emergency Dashboard - Yemen Report Dec 2020. Roma (IT): WFP. 